\title{
Intraspecific variation in growth and allocation patterns in seedlings of Pinus pinaster Ait. submitted to contrasting watering regimes: can water availability explain regional variation?
}

\author{
David SÁNCHEZ-Gómez ${ }^{1,2 *}$, Juan MAJADA ${ }^{3}$, Ricardo AlíA $^{3,4}$, Isabel FeITO $^{3}$, Ismael ARANDA $^{2,4}$ \\ ${ }^{1}$ Grupo de Investigación de Genética y Fisiología Forestal, ETSI Montes, UPM, Ciudad Universitaria s/n, Madrid, 28040, Spain \\ ${ }^{2}$ Unidad Mixta de Genómica y Ecosifiología Forestal, INIA-UPM, Spain \\ ${ }^{3}$ SERIDA, Estación Experimental La Mata, Sección Forestal, Grado, Asturias, 33820, Spain \\ ${ }^{4}$ Departamento de Sistemas y Recursos Forestales, CIFOR, Instituto Nacional de Investigación y Tecnología Agraria (INIA), \\ Carretera de La Coruña, Km. 7.5, Madrid 28040, Spain \\ ${ }^{5}$ Sustainable Forest Management Research Institute UVa-INIA, Spain
}

(Received 14 May 2009; accepted 12 November 2009)

Keywords:

Altitude /

drought tolerance /

Mediterranean basin /

mixed models /

whole plant performance

Mots-clés :

altitude /

tolérance à la sécheresse /

Bassin méditerranéen /

modèles mixtes /

performance du plant entier

\begin{abstract}
- Interpopulation variation in key functional traits of Pinus pinaster Ait. is well recognized. However, the relative importance of drought tolerance to explain this regional variation in the species remains elusive.

- Here, we raise the question whether water availability constitutes a likely driver of regional variation in biomass allocation, growth and morphological traits of ten populations that cover the distribution range of $P$. pinaster. We carried out an experiment where seedlings of five families per population were submitted to two contrasting watering treatments.

- The effects of water availability and population were significant for relative diameter and height growth rate, biomass allocation and number of lateral stems and dwarf shoots. Total dry mass significantly differed between watering treatments but it did not among populations. Populations could be clustered into four main groups. Root mass fraction explained most of the variation and significantly correlated to altitude but not to aridity.

- The geographical pattern of genetic variation found in morphology and biomass allocation did not translate into population differences in drought tolerance or phenotypic plasticity to water availability, indicating that water availability is not a likely driver of the regional variation observed in the studied traits of $P$. pinaster at the seedling stage.
\end{abstract}

Résumé - Variation intra-spécifique de la croissance et de l'allocation de biomasse de semis de Pinus pinaster Ait. soumis à des régimes d'arrosage contrastés : la disponibilité en eau peut elle expliquer les variations régionales?

- La variabilité de traits fonctionnels clés entre populations de Pinus pinaster Ait. est bien connue. Cependant, l'importance relative de la tolérance à la sécheresse pour expliquer cette variabilité régionale reste difficile à cerner.

- Ici, nous testons l'hypothèse selon la quelle la disponibilité en eau constitue un moteur des variations régionales, de répartition de biomasse, de croissance et de traits morphologiques dans dix populations qui couvrent la zone de répartition de $P$. pinaster. Nous avons mené une expérience où les semis de cinq familles par population ont été soumis à deux régimes d'irrigation contrastés.

- Les effets de la disponibilité en eau et de la population ont été importants sur le diamètre et le taux relatif de croissance en hauteur, la répartition de la biomasse et le nombre de tiges latérales et de pousses courtes. La masse sèche totale différait sensiblement entre les traitements d'arrosage, mais pas entre les populations. Les populations pourraient être regroupées en quatre groupes principaux. La fraction de masse racinaire expliquait la plupart des variations et est significativement corrélée à l'altitude mais pas à l'aridité.

- La répartition géographique de la variation génétique de morphologie et de répartition de la biomasse, ne se traduit pas en différences de résistance à la sécheresse ou de plasticité phénotypique à la disponibilité en eau. Cela indique que la disponibilité en eau n'est pas un moteur des variations régionales observées dans les traits foinctionnels de $P$. pinaster au stade semis.

\footnotetext{
* Corresponding author: david.sango@gmail.com
} 


\section{INTRODUCTION}

Interspecific variation in key functional traits along environmental gradients can explain adaptive patterns related to tolerance to limiting resources such as light and water (e.g. Barton, 1993; Shugart, 1984). This is also expected to occur at an intraspecific level which would explain patterns of adaptive variation among different populations along the geographic range of the species. Thus, characterization of that variation within forest tree species is important to understand the interplay and significance of evolutionary forces and to carry out appropriate and genetically sound breeding programs (White et al., 2007).

Water availability is one of the most important limiting resources for recruitment of Mediterranean forest tree species and shrubs (Pigott and Pigott, 1993). Consequently, adaptive mechanisms involved in drought tolerance are expected to underlie the distribution of populations along natural gradients of water availability. Since the limiting nature of water availability is predicted to be exacerbated in this area due to Climate Change (IPCC, 2007), understanding the role of such drought tolerance mechanisms on the evolutionary process and regional differentiation of populations constitutes a central goal in Forest Science.

A number of morphological traits and patterns of biomass allocation have been described as potential mechanisms conferring drought tolerance. For example high investment to roots and low investment to needles are predicted to confer drought tolerance by maximizing water capture and minimizing water losses through transpiration (Ludlow, 1989). In agreement with this idea, several studies on pines, have found high root investment (Cregg and Zhang, 2001; Nguyen and Lamant, 1989) and low specific leaf area (Fernández et al., 1999) in populations from dry sites. However, this pattern might not be general since the relationships among traits linked to drought tolerance might change depending on the species (Zhang et al., 1996). For water use efficiency (WUE), a well studied trait related to plant water economy, contrasting results have been found. For example, WUE has been reported to be positively correlated to the aridity of the native habitat (e.g. Anderson et al., 1996). However, the reverse pattern has also been found (e.g Nguyen-Queyrens et al., 1998; Zhang et al., 1997). This might be reflecting constraints and trade-offs that arise when multiple interacting factors co-occur. For example, high WUE could enhance productivity and survival of plants in dry environments (Jones, 1993) but a water-spending strategy could be more adaptive when competition pressure is taken into account (Cohen, 1970).

Pinus pinaster Ait. is a wind-pollinated outcrossing conifer distributed along the Mediterranean basin with important but fragmented populations all over the western range. Geographic variation in molecular markers and quantitative traits has been previously described for this species (GonzálezMartínez et al., 2002; Guyon and Kremer, 1982) in agreement with the different ecological conditions where populations of $P$. pinaster are found. Six main gene pools have been described for the species (Bucci et al., 2007): Continental France, Corsica, Northwestern and Central Spain, South- ern Spain, Morocco and Tunisia. Although contrasting water availability is assumed to occur along the populations of these six major groups, studies assessing intraspecific variation in morphology and biomass allocation patterns as potential mechanism involved in drought tolerance differentiation in this species are scant. Besides, to our knowledge, there is no study assessing whether that intraspecific variation is linked to drought tolerance in terms of seedlings' whole plant performance. A drought tolerant phenotype can be particularly important for seedlings since their small root development makes them very vulnerable to drought. In fact, the seedling stage is a critical part of the tree's life cycle because seedlings have great susceptibility to resource limitations that affect establishment and growth (Leck et al., 2008).

In this study, we investigated the intraspecific variability in whole plant performance, biomass allocation and selected morphological traits in seedlings of $P$. pinaster submitted to two experimental watering treatments. Three main hypotheses were tested: (1) intraspecific differences in selected functional traits exist in the studied populations of $P$. pinaster at the seedling stage; (2) drought tolerance and phenotypic plasticity to water availability explain intraspecific variation in the studied functional traits; (3) regional variation in aridity correlates to intraspecific variation in functional traits linked to drought tolerance.

\section{MATERIALS AND METHODS}

\subsection{Plant material}

Ten autochthonous populations of $P$. pinaster were selected along a latitudinal cline (see Tab. I for details): seven Spanish populations (ARMY, ASPE, CDVO, COCA, ORIA, PTOV, SCRI), two French population (MIMI and PLEU) and one Moroccan population (TAMR). Within each population, seeds were collected from five mother trees with a separation distance of more than $50 \mathrm{~m}$ among them to avoid inbreeding. Thus, fifty open-pollinated families were available for the experiment. Some of the selected populations have previously been tested in field provenance trials, although not at the juvenile stage (Alía et al., 1995).

\subsection{Experimental conditions}

The experiment was conducted in a greenhouse under natural light, controlled temperature and vapour pressure deficit $(1.0 \mathrm{kPa})$ with a proper mixing of the air around seedlings. The greenhouse was located in SERIDA (Asturias, Spain) at $43^{\circ} 23^{\prime} \mathrm{N} 6^{\circ} 4^{\prime} \mathrm{W}$ at $60 \mathrm{~m}$ a.s.l. Seeds were sown in $400 \mathrm{~cm}^{3}$ pots with a mixture of vermiculite and grade 3 peat (20:80 v:v peat "VP BOW", fertilized with NPK 15:8:12, at $1.5 \mathrm{~kg} \mathrm{~m}^{3}$ ) on 12 April 2004. After germination, five hundred seedlings accounting for 5 replicates per family and watering regime in each population were arranged in a complete random block design, with ten blocks. Each block contained one replicate for each family. Seedlings of different families and populations were randomized within the block. After a growing period of $104 \mathrm{~d}$ (watering to full capacity, $20{ }^{\circ} \mathrm{C}$ and $90 \%$ of $\mathrm{RH}$ ) seedlings had an average height of $25.54 \pm 0.04$ (mean \pm standard error, $\mathrm{mm}$ ) and a 
Table I. Location and climatic details of the studied populations. Climatic data for MIMI, PLEU and TAMR are derived from the WorldClim database. Data for the Spanish populations are obtained from a regional model (see Materials and methods).

\begin{tabular}{|c|c|c|c|c|c|c|c|}
\hline Code & Population & Country & Latitude and longitude & $\begin{array}{l}\text { Mean altitude } \\
\text { range }(\mathrm{m})\end{array}$ & $\begin{array}{c}\text { Annual } \\
\text { rainfall }(\mathrm{mm})\end{array}$ & $\begin{array}{c}\text { Mean annual } \\
\text { temperature }\left({ }^{\circ} \mathrm{C}\right)\end{array}$ & Aridity index \\
\hline$\overline{\text { ARMY }}$ & Armayán & Spain & $43^{\circ} 18^{\prime} \mathrm{N} 6^{\circ} 29^{\prime} \mathrm{W}$ & 532 & 1160 & 11.8 & 0 \\
\hline ASPE & Arenas de San Pedro & Spain & $40^{\circ} 12^{\prime} \mathrm{N} 5^{\circ} 3^{\prime} \mathrm{W}$ & 728 & 1318 & 14.2 & 69.4 \\
\hline $\mathrm{CDVO}$ & Cadavedo & Spain & $43^{\circ} 32^{\prime} \mathrm{N}^{\circ} 25^{\prime} \mathrm{W}$ & 180 & 1316 & 13.2 & 0.8 \\
\hline COCA & Coca & Spain & $41^{\circ} 15^{\prime} \mathrm{N} 4^{\circ} 30^{\prime} \mathrm{W}$ & 780 & 454 & 12.3 & 51.4 \\
\hline MIMI & Mimizan & France & $44^{\circ} 12^{\prime} \mathrm{N} 1^{\circ} 13^{\prime} \mathrm{W}$ & 20 & 935 & 13.2 & 0 \\
\hline ORIA & Oria & Spain & $37^{\circ} 30^{\prime} \mathrm{N} 2^{\circ} 20^{\prime} \mathrm{W}$ & 1150 & 357 & 13.1 & 110 \\
\hline PLEU & Pleucaeuc & France & $47^{\circ} 47^{\prime} \mathrm{N} 2^{\circ} 20^{\prime} \mathrm{W}$ & 80 & 855 & 12.0 & 0 \\
\hline PTOV & Puerto de la Vega & Spain & $43^{\circ} 33^{\prime} \mathrm{N} 6^{\circ} 38^{\prime} \mathrm{W}$ & 98 & 1283 & 13.4 & 4.9 \\
\hline SCRI & San Cipriano & Spain & $42^{\circ} 07^{\prime} \mathrm{N} 8^{\circ} 22^{\prime} \mathrm{W}$ & 727 & 1600 & 12.3 & 15.8 \\
\hline TAMR & Tamrabta & Morocco & $33^{\circ} 36^{\prime} \mathrm{N} 5^{\circ} 01^{\prime} \mathrm{W}$ & 1760 & 763 & 10.8 & 67.9 \\
\hline
\end{tabular}

root collar diameter of $1.22 \pm 0.01$ (mean \pm standard error, $\mathrm{mm}$ ). At that time, five blocks were submitted to either a well watered regime (WW) or a water deficit regime (WD) for 96 days. The two watering regimes were based on the saturation level of the substrate: in WW the substrate was kept at $90-100 \%$ of the mean saturation level, and in WS the substrate was kept at $40 \%$ of the mean saturation level. The amount of water supplied daily was determined by weighting ten individuals randomly chosen from each watering regime $\times$ population combination. The following macro and micronutrients $\left(\mathrm{mg}\right.$ plant $^{-1}$ week $\left.{ }^{-1}\right)$ were applied: $\mathrm{N}(9,27), \mathrm{PO}_{4}^{-3}(4,25), \mathrm{K}(7,45), \mathrm{Mg}^{2+}(0$, 038), Mo (0, 006), Fe (0, 064), Mn (0, 042), Zn (0, 006), B (0, 006) and $\mathrm{Cu}(0,032)$. Fertilization was done twice while seedlings were submitted to the watering treatment.

\subsection{Measured variables}

Seedling height (length of the main stem; accuracy $5 \mathrm{~mm}$ ) and root collar diameter (measured with a calliper; accuracy $0.01 \mathrm{~mm}$ ) for each individual were recorded three times during the experiment: $t_{1}=1, t_{2}=51$ and $t_{3}=96 \mathrm{~d}$ after the watering treatment period. Relative height growth rate (RhGR) and relative diameter growth rate (RdGR) were estimated for each seedling in three intervals during the experiment $\left(t_{1}-t_{2}, t_{2}-t_{3}\right.$ and $\left.t_{1}-t_{3}\right)$ to account for temporal variations in above ground architecture among families and populations. RhGR and RdGR were calculated as $\left(\ln G_{i}-\ln G_{j}\right) /\left(t_{i}-t_{j}\right), G_{i}$ and $G_{j}$ being the height or root collar diameter in time $i$ and $j\left(t_{i}\right.$ and $t_{j}$ respectively, with $i>j$ ).

At the end of the experiment (200 d after sowing), the number of lateral stems (secondary stems grown from axillary buds of the main stem) were recorder and all the seedlings were harvested and fractioned into needles, dwarf shoots, stems and roots. Dry mass of each fraction, was determined after oven-drying for $2 \mathrm{~d}$ at $70^{\circ} \mathrm{C}$. Substrate fresh and dry weights were determined similarly at this point. The following variables were derived: number of lateral stems, substrate relative water content (sRWC, [substrate fresh weight - substrate dry weight $]$ /substrate dry weight), total dry mass ( $g$ ), root-shoot ratio $\left(\mathrm{g} \mathrm{g}^{-1}\right)$, needle mass fraction (NMF, $\mathrm{g} \mathrm{g}^{-1}$ ), root mass fraction (RMF, $\mathrm{g} \mathrm{g}^{-1}$ ), stem mass fraction (SMF, $\mathrm{g} \mathrm{g}^{-1}$ ). Seedlings' roots were not pot-bound which indicates that pot size did not limit root development throughout the experiment.

\subsection{Statistical analyses}

The following model was established for all the variables:

$y_{i j k m n}=\mu+c_{i j k m n}+t_{i}+p_{j}+t p_{i j}+\varphi_{k(j)}+t \varphi_{i k(j)}+\beta_{m}+\varepsilon_{i j k m n}$

where; $y_{i j k m n}$ is the value of the variable for the $n$ th-seedling from the $k$ th-family within $j$ th-population, located in the $m$ th-block in the $i$ thtreatment, $\mu$ is overall mean, $c_{i j k m n}$ is the effect of a covariate (seedling height at the beginning of the watering treatment), $t_{i}$ is the effect of the $i$ th-treatment (WW or WS, $1-2$ ), $p_{j}$ is the effect of the $j$ th-population $(1-10), \phi_{k(j)}$ is the effect of the $k$ th-family within the $j$ th-population (1-5), $\beta_{m}$ is the effect of the $m$ th-block (1-5) and $\varepsilon_{i j k l m n}$ is the experimental error. The interaction terms $t p_{i j}$ and $t \phi_{i k(j)}$ were also included in the model. A significant watering treatment by population interaction for a particular variable would indicate significant differences in the phenotypic plasticity between populations (Schlichting, 1986) for that variable.

The model was analyzed as a general linear model (GLM) with fixed (block, watering treatment, population) and random (family) effects. Shapiro-Wilk's W and Levene's tests were used to test for normality and homogeneity of variances respectively. Log-transformed variables were used when necessary to meet the assumptions of normality and homocedasticity required for the analysis of the model.

Heritability (narrow sense) over populations, $h^{2}$, was calculated for each variable after removing the population component from each family:

$$
h^{2}=\frac{V_{A}}{V_{P}}=\frac{4 V_{\mathrm{fam}}}{V_{\mathrm{fam}}+V_{e}}
$$

where $V_{P}$ is the phenotypic variance, $V_{A}$ is the additive variance, $V_{\mathrm{fam}}$ is the family variance, and $V_{e}$ is the error variance. The standard error of heritability was calculated following the classical approach from Osborne and Paterson (Visscher, 1998):

$$
S E_{h^{2}}=4 x \sqrt{\frac{2\left(1-\frac{h^{2}}{4}\right)^{2}\left[\left(1+(s-1) \frac{h^{2}}{4}\right]^{2}\right.}{s(s-1)(f-1)}}
$$

where $s$ is the number of offspring per family and $f$ the number of families.

Genetic differentiation among populations for quantitative characters, $Q_{S T}$, was calculated using the following expression:

$$
Q_{S T}=\frac{V_{\text {pop }}}{V_{\text {pop }}+2\left(V_{A}\right)}
$$

where $V_{\text {pop }}$ is the population variance. 


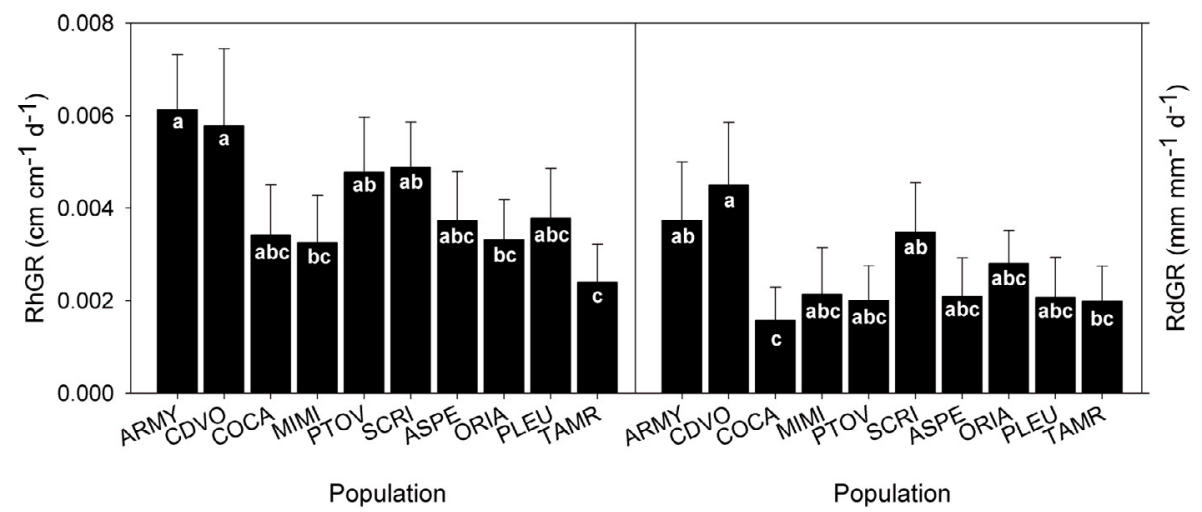

Figure 1. Relative height (RhGR) and diameter (RdGR) growth rates for sept-oct interval under water deficit. Letter codes denote homogeneous groups (GLM, Tukey-HSD test, $p<0.05)$ among populations.

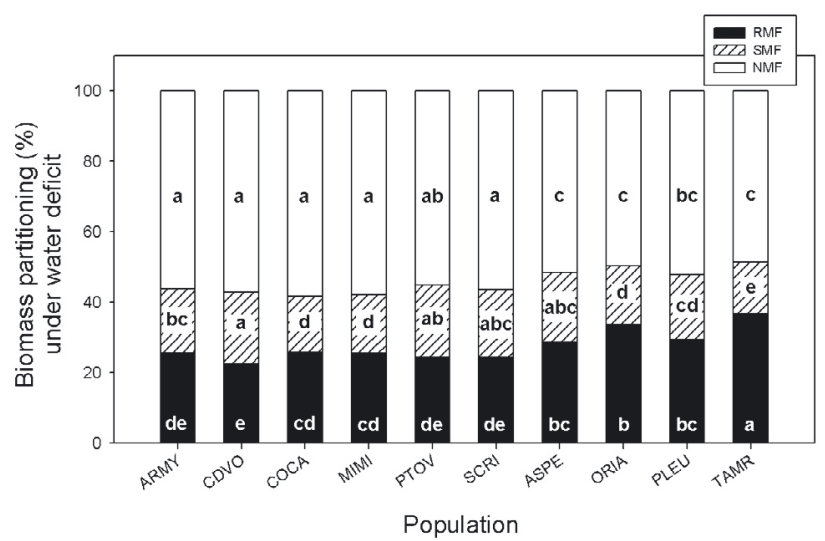

Figure 2. Stacked bars representing root mass fraction (RMF), stem mass fraction (SMF) and needle mass fraction (NMF) under water deficit for a fixed initial height of $25 \mathrm{~mm}$. Letter codes denote homogeneous groups (GLM, Tukey-HSD test, $p<0.05$ ) among populations for each biomass compartment.

A principal components analysis (PCA) was performed for the subset of data under water deficit in order to identify potential homogeneous groups among populations in allocation and growth traits under limiting water. Only those variables with significant population effect were included in this analysis. A varimax rotation was done to maximize the variation of factor loadings and help the interpretation of the factors.

Finally, given that RMF was the trait that contributed the most to the first Principal Component (see Results), we analysed its correlation (Spearman rank correlation) to key environmental indicators potentially linked to gradients in water availability. An aridity index, latitude and altitude were the selected indicators. The aridity index was derived from Bagnouls-Gaussen index (Bagnouls and Gaussen, 1953) and was calculated as:

$$
A I=\sum_{i=1}^{i=12} 2 T_{i}-P_{i} \quad \forall i \ni 2 T_{i} \geqslant P_{i}
$$

where $i$ stands for month (January $=1 \ldots$, December $=12), T_{i}$ stands for mean temperature $\left({ }^{\circ} \mathrm{C}\right)$ in month $i$ and $P_{i}$ stands for mean pre- cipitation $(\mathrm{mm})$ in month $i$. Climatic data for the Spanish populations were obtained from a regional climate model which has been proven to provide good estimates for these region (Gonzalo, 2008). Climatic data for French and Moroccan populations were taken from the WorldClim database (1950-2000 period, http://www.worldclim. org).

Analysis of variance, rank correlations and PCA were done with STATISTICA v. 6.0 (Statsoft Inc., Tulsa, OK, USA).

\section{RESULTS}

\subsection{Effects of the factors}

The block effect was not significant (GLM, $P<0.05$ ) across all the studied variables. Thus, the block factor was removed from the models for parsimony. Substrate gravimetric water content at the end of the experiment significantly differed between watering treatments (WW: $58.05 \pm 1.05$; WD: $43.15 \pm 0.91$, mean and standard error respectively) and no interaction between watering treatment and population was found for this variable (GLM, $F=1.34, p=0.235$ ), indicating the effect of the watering treatment was the same among populations.

The effect of watering regime was significant for all the studied variables except number of lateral stems, and RMF (Tab. II). Water deficit decreased total dry mass, RhGR, RdGR, SMF, and number of dwarf shoots while increased NMF.

The population effect was significant for all the variables except total dry mass, RdGR (Jul-Sept), and RdGR (Jul-Oct). The population ranking for RhGR and RdGR did not change across intervals. Specific differences among populations are shown in Figure 1 for RhGR and RdGR, in Figure 2 for biomass partitioning and in Figure 3 for number of lateral stems and dwarf shoots.

The effect of the family nested in population was significant for total dry mass, and marginally significant for RdGR (Jul-Oct), RhGR (Sep-Oct) and SMF (Tab. II). The effect of the covariate initial height was significant for all the studied 
Table II. Results of the GLMs for the studied variables. WR stands for water regime, Pop stands for population, Fam (Pop) stands for family nested in population and $\mathrm{C}$ stands for the covariate initial height. RdGR $(i-j)$ stands for relative diameter growth rate in the time interval $i-j$, RhGR $(i-j)$ stands for relative height growth rate in the time interval $i-j$, RMF stands for root mass fraction, SMF stands for stem mass fraction, NMF stands for needle mass fraction. The degrees of freedom for each factor/covariate are given in brackets by the caption F-value. One star denotes $p<0.05$, two stars denote $p<0.01$ and three stars denote $p<0.001$.

\begin{tabular}{|c|c|c|c|c|c|c|}
\hline Variables & \multicolumn{6}{|c|}{ Factor/covariate } \\
\hline Total dry mass & $141.5^{* * *}$ & 1 & $2.3 * * *$ & 0.9 & 1.3 & $29.6^{* * *}$ \\
\hline RdGR (Sept-Oct) & $54.96 * * *$ & $2.82 * *$ & 0.78 & 0.78 & 1.03 & $15.89 * * *$ \\
\hline RdGR (Jul-Oct) & $74.14 * *$ & 0.77 & $2.45^{*}$ & 0.92 & 1.23 & 9.51 \\
\hline RhGR (Jul-Sept) & $41.5^{* * *}$ & $14.1 * * *$ & 1.4 & 1.3 & 0.8 & $845.6^{* * *}$ \\
\hline RMF & 1.21 & $16.91 * * *$ & 1.19 & 0.57 & 1.13 & $14.25 * * *$ \\
\hline SMF & $52.6 * * *$ & $10.92 * * *$ & $1.77 *$ & 1.28 & 1.18 & $12.49 * * *$ \\
\hline NMF & $11.23 * *$ & $12.17 * * *$ & 1.01 & 1.56 & 1.07 & $4.27 *$ \\
\hline No lateral stems & 1.9 & $4.37 * * *$ & 1.47 & 0.69 & 1.23 & $4.54 *$ \\
\hline No dwarf shoots & $35.61 * * *$ & $4.5^{* * *}$ & 1.11 & 1.06 & 1.11 & $12.09 * *$ \\
\hline
\end{tabular}

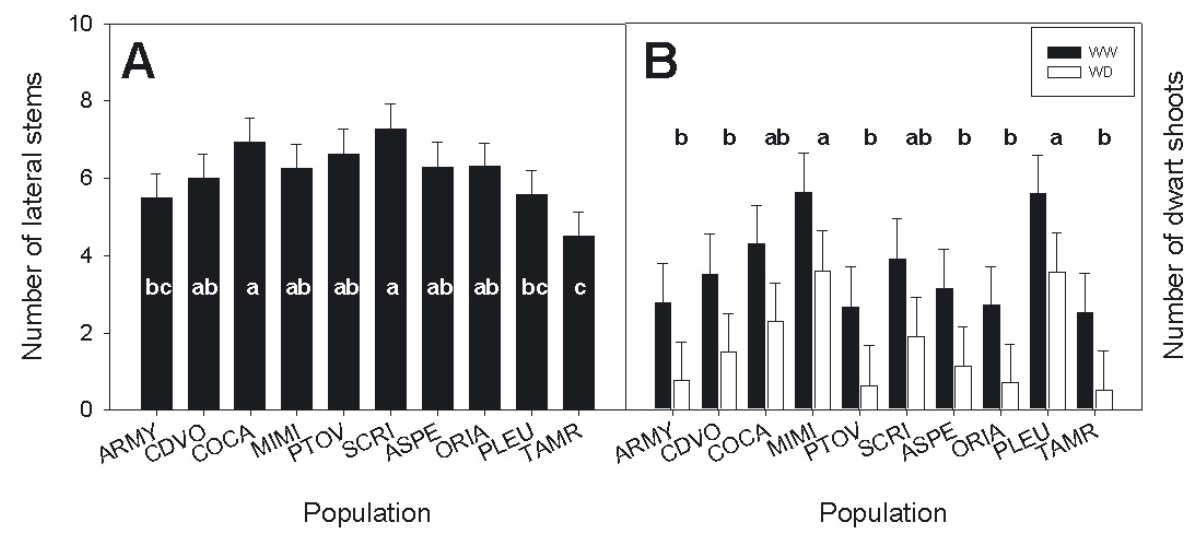

Figure 3. Number of lateral stems (A) and dwarf shoots (B) for a fixed initial height of $25 \mathrm{~mm}$. Graph A represents the number of lateral stems for each population regardless of the watering regime since the effect of this factor was not significant on the number of lateral stems. Graph B represents the number of dwarf shoots for each population $\times$ water regime (well-watered, WW and water deficit, WD). Error bars denote $95 \%$ confidence intervals. Letter codes denote homogeneous groups (GLM, Tukey-HSD test, $p<0.05)$ among populations.

variables but RdGR (Jul-Sept) and RdGR (Jul-Oct). The interaction terms of the model were not significant for any of the studied variables (Tab. II).

Significant heritability values (mean \pm se provided) were obtained for total dry mass $(0.69 \pm 0.18)$, RhGR (Sept-Oct, $0.59 \pm 0.17)$ and SMF $(0.32 \pm 0.13)$. Quantitative differentiation among populations ( $Q_{S T}$ values) was very low for total dry mass and $\operatorname{RhGR}\left(Q_{S T}=0.0\right.$ and 0.06 respectively), but it was high for SMF (0.43).

\subsection{PCA results and rank correlations}

The first two principal components (eigenvalue $>1$ ) explained up to $57.54 \%$ of the total variance of the data under water deficit. The first component (PC1) explained $38.37 \%$ of the total variance. This component was positively correlated to NMF and negatively correlated to RMF. RMF was the variable that contributed the most to PC1 (Tab. III). The second component (PC2) explained $19.17 \%$ of the total variance. This component was positively correlated to RdGR and RhGR but negatively correlated to the number of dwarf shoots (refer to Tab. III to see the contribution of each variable to the principal components).

PC1 and PC2 clustered the ten populations into four main groups (Fig. 4). According to PC1, the group constituted by TAMR was defined by high allocation to roots, low allocation to stem and low potential of height and diameter growth. Another group constituted by CDVO, PTOV, ARMY and SCRI were defined by the opposite pattern: high allocation to stem, high potential of height and diameter growth and low allocation to roots. MIMI, COCA, ASPE, PLEU and ORIA showed intermediate values for these traits. However, MIMI and COCA had higher allocation to needles, lower allocation 


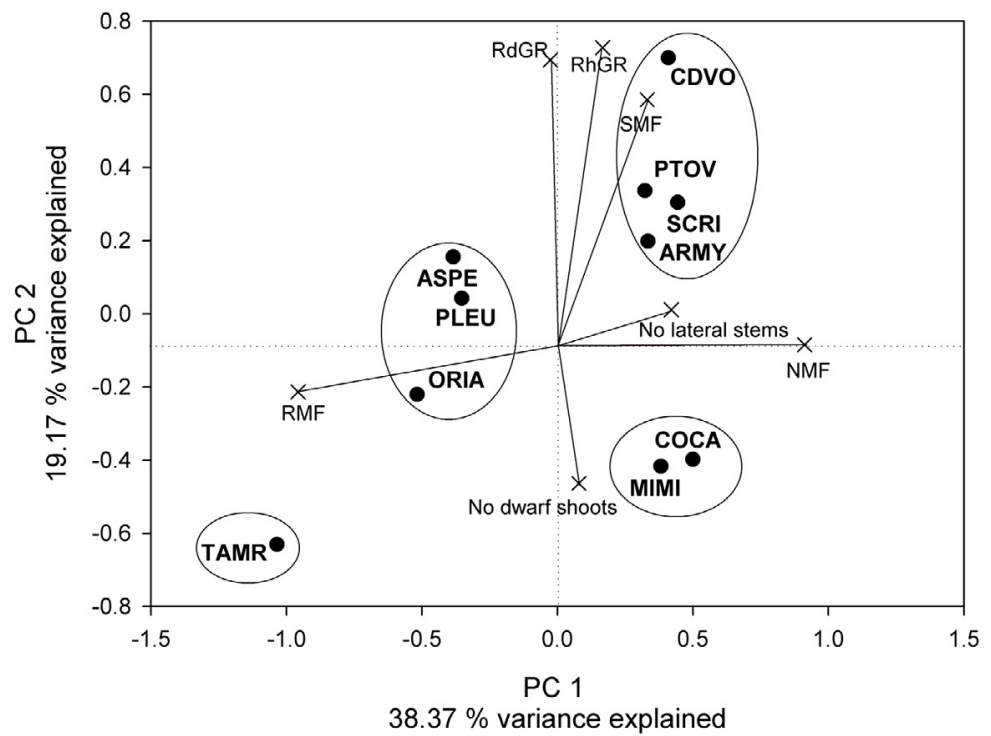

Figure 4. PCA results showing the factor coordinates of the variables $(\times)$ and populations $(\bullet)$ on the plane defined by the two Principal Components. A varimax rotation of the axes was performed. The ellipses denote the four different groups than can be defined according to the position of populations on the plane.

Table III. Contribution weight of each variable to the Principal components (PC) based on correlations. The star denotes the highest contributions to each PC. The percentage of the total variance explained by $\mathrm{PC} 1$ and $\mathrm{PC} 2$ is also provided.

\begin{tabular}{lcc}
\hline \multirow{2}{*}{ Variables } & \multicolumn{2}{c}{ Principal component } \\
\cline { 2 - 3 } & PC1 $(38.37 \%)$ & PCA2 $(19.17 \%)$ \\
\hline RhGR & $0.17^{*}$ & $0.73^{*}$ \\
RdGR & -0.03 & $0.69^{*}$ \\
SMF & 0.33 & 0.59 \\
RMF & $-0.96^{*}$ & -0.21 \\
NMF & $0.91^{*}$ & -0.08 \\
No lateral stems & 0.41 & 0.01 \\
No dwarf shoots & 0.08 & -0.46 \\
\hline
\end{tabular}

to roots and lower potential of growth than ASPE, PLEU and ORIA.

RMF significantly and positively correlated to altitude (Spearman- $R=0.66, p<0.04$ ) but it did not to either latitude or aridity (Spearman- $R=-0.55$ and 0.47 respectively).

\section{DISCUSSION}

\subsection{Intraspecific variation}

Inter- and intrapopulation variation was found in one-year old seedlings of Pinus pinaster Ait. with respect to height and diameter growth, aboveground structure (branching and presence of dwarf shoots) and biomass allocation patterns at the whole plant level (RMF, SMF and NMF). The low heritability found in biomass allocation suggests that biomass allocation has experienced an adaptive differentiation process in response to the local climatic conditions of each population. Moreover, the fact that most of the studied variables varied among populations denotes a significant geographic pattern of genetic variation for this species in agreement with previous studies (e.g. Alía et al., 1997; Danjon, 1994). However, whether this variation correlates to geographic gradients linked to water availability remains unknown, particularly for biomass allocation, a key functional trait involved in carbon balance at the whole plant level (Poorter, 2001) and in the competitive ability of the species along resource gradients (Aerts et al., 1991). Water availability has been found to influence biomass allocation (Chapin, 1980). In particular, different allocation patterns might be predicted along a water availability gradient as an adaptive mechanism that allows maximizing carbon gain and minimizing water losses. According to biomass allocation and growth, the studied populations could be clustered in four separated groups. One group (including only the Moroccan population) had high investment to roots and low investment to needles (transpiring organs) which conforms to a drought tolerant phenotype as it would allow both maximize water capture and minimize water losses (Ludlow, 1989). Another group (clustering the four populations from the north of the Iberian Peninsula) conformed to a drought intolerant but fast growing phenotype with the opposite pattern. The remaining two groups (clustering populations from France and Central Spain) exhibited intermediate phenotypes in terms of potential of growth and root allocation. Although these range of phenotypes might conform well to an adaptive mechanism involved in maximizing plant performance along a water availability gradient, our results point out that the observed phenotypic variation is better explained by altitude than by aridity. Similarly, in a close study, it was found that the water use efficiency shown by TAMR was related to the altitudinal position of this population and not to drought tolerance (Aranda et al., 2009). 
There are many other factors apart from water availability such as irradiance (Popma and Bongers, 1988), nutrients (Müller et al., 2000) and temperature (Wilson, 1988) that can also influence biomass allocation and accumulation, and all of them are expected to vary with altitude (Körner, 2003). Despite altitude as a whole has been reported to influence the regional variation in selected traits of $P$. pinaster (Alía et al., 1997; Wahid et al., 2006) and other species (Cordell et al., 1998; Sáenz-Romero et al., 2006), further research is needed to unveil which specific correlate of altitude is the main and direct driver of this pattern.

\subsection{Impact of water deficit on the studied traits: intraspecific differences}

Water deficit impacted on most of the studied traits. Its impact on total dry mass and on height and diameter growth translated into lower performance in comparison to seedlings grown in well watered conditions. The number of dwarf shoots was also reduced by drought. The occurrence of dwarf shoots in pine seedlings is a sign of maturity which can be used to evaluate the ontogenetic stage of the seedling (Chambel et al., 2007). Thus, the results from both seedlings' growth and number of dwarf shoots, taken together, suggest that water deficit reduces carbon gain and slows down ontogenetic development in this, like in many other species.

The impact of drought on biomass allocation was very mild in comparison to the rest of variables studied. In fact, drought exerted changes in biomass allocation only within the aboveground compartment but not in root investment (belowground compartment). According to the optimal foraging theory, a plant should adjust its physiology and morphology in order to be equally limited by all essential resources (Tilman, 1988). Consequently, biomass allocation to roots rather than to shoot might be the expected response to drought (Bloom et al., 1985). However, more recently it has been hypothesized that the impacts of drought on shoot growth and photosynthesis might counterbalance this shift resulting in modest changes in root investment under drought (Poorter and Nagel, 2000). The same idea is supported by another study (SánchezGómez et al., 2008) where only four out of eight Mediterranean species moderately increased their RMF under drought.

If a seedling keeps invariable the biomass allocated to needles and shortens the internodes' length in response to drought, it would result in an increased allocation to needles and a decreased allocation to stem as compared with the pattern the seedling would show under well watered conditions. This response matches the results found in this study and suggests lengthening or shortening the internodes might be the only potential adjustments that a phenotype previously developed under non-limiting water availability might make in response to drought. Although a reduced leaf area may increase plant growth when water is limiting as a mechanism that increases the water use efficiency (Richards and Townley-Smith, 1987), such adjustment might not always be possible, in particular, if allocation to different compartments are submitted to developmental constraints. For Pinus pinaster, phenotypes preacclimated to non-limiting water availability might constrain their capability to modify biomass allocation in order to maximize whole plant carbon gain under an eventual drought.

It is noteworthy that the impact of drought on all the studied traits did not vary among populations or families between populations. This fact, when evaluated on whole plant performance (total dry mass), and together with the lack of interpopulation differences in total dry mass, denotes similar drought tolerance among populations. Moreover, when the impact is evaluated on morphological traits and allocation, it denotes similar phenotypic plasticity in response to drought at an intraspecific level. In agreement with interpopulation homogeneity in drought tolerance, Fernández et al. (2000) did not find differences among populations in gas exchange variables in seedlings of $P$. pinaster submitted to contrasting watering regimes. In contrast, intraspecific variation in physiological mechanisms involved in drought tolerance has been reported in three-years-old individuals of this species (Nguyen-Queyrens and Bouchet-Lannat, 2003). However, intraspecific variation in physiological or morphological traits may not translate into intraspecific variation in whole plant performance in response to drought as found in this study. Therefore, when assessing plant responses to different water regimes, it is important that potential mechanisms involved in drought tolerance are contrasted jointly with whole plant performance variables (e.g. biomass accumulation at the whole plant level or survival) which as early indices of fitness, they provide estimates of drought tolerance at a specific ontogenetic stage or tree age.

The findings of this study explain patterns that have arisen in a particular experimental setting (seedlings, two levels of water availability, and ten populations of $P$. pinaster). Thus, generalizations should be made with caution. Further studies are needed to test whether these findings hold when other populations are evaluated and saplings or mature trees are studied instead of seedlings.

\section{CONCLUSIONS}

Interpopulation differences were found in morphology and biomass allocation of seedlings of $P$. pinaster. However, such differences did not translate into intraspecific differences in response to drought. Specifically, drought tolerance and phenotypic plasticity to water availability did not differ among populations. In agreement with these findings, altitude and not aridity was the climatic factor that better explained the regional variation observed in the studied traits.

Acknowledgements: This study was funded by the project RTA2007-00084-00-00, the European Project TREESNIP-QLK3CT2002-01973 and the project AGL2006-03242. Ernesto Alvarez provided technical support during the experiment, and Fernando del Caño, Sara Herrera and Neila Godoy kindly helped during the harvest of seedlings. D.S.-G. was supported by the "Juan de la Cierva" program granted by the Spanish Ministry of Science and Innovation.

\section{REFERENCES}

Aerts R., Boot R.G.A., and van der Aart P.J.M., 1991. The relation between above- and belowground biomass allocation patterns and competitive ability. Oecologia 87: 551-559. 
Alía R., Gil L., and Pardos J.A., 1995. Performance of 43 Pinus-pinaster Ait. provenances on 5 locations in central Spain. Silvae Genet 44: $75-81$.

Alía R., Moro J., and Denis J.B., 1997. Performance of Pinus pinaster provenances in Spain: interpretation of the genotype by environment interaction. Can. J. For. Res. 27: 1548-1559.

Anderson J.E., Williams J., Kriedeman P.E., Austin M.P., and Farquhar G.D., 1996. Correlations between carbon isotope discrimination and climate of native habitats for diverse eucalypt taxa growing in a common garden. Aus. J. Plant Physiol. 23: 311-320.

Aranda I., Alía R., Ortega U., Dantas A.K., and Majada J., 2010. Intraspecific variability in biomass partitioning and carbon isotopic discrimination under moderate drought stress in seedlings from four Pinus pinaster populations. Tree Genet. Genomes 6: 169-178.

Bagnouls F. and Gaussen H., 1953. Saison sèche et indice xérothermique. Bull. Soc. Hist. Nat. Toulouse 88: 193-239.

Barton A.M., 1993. Factors controlling plant distributions: drought, competition, and fire in montane pines in Arizona. Ecol. Monogr. 63: 367-397.

Bloom A.J., Chapin F.S., and Mooney H.A., 1985. Resource limitation in plants - an economic analogy. Ann. Rev. Ecol. Syst. 16: 363-392.

Bucci G., González-Martínez S.C., et al., 2007. Range-wide phylogeography and gene zones in Pinus pinaster Ait. reveales by chloroplast microsatellite markers. Mol. Ecol. 16: 2137-2153.

Chambel M.R., Climent J., and Alía R., 2007. Divergence among species and populations of Mediterranean pines in biomass allocation of seedlings grown under two watering regimes. Ann. For. Sci 64: $87-97$.

Chapin F.S., 1980. The mineral nutrition of wild plants. Ann. Rev. Ecol Syst. 11: 233-260.

Cohen D., 1970. Expected efficiency of water utilization in plants under different competition and selection regimes. Isr. J. Bot. 19: 50.

Cordell S., Goldstein G., Müller-Dombois D., Webb D., and Vitousek P.M., 1998. Physiological and morphological variation in Metrosideros polymorpha, a dominant Hawaiian tree species, along an altitudinal gradient: the role of phenotypic plasticity. Oecologia 113: 188-196.

Cregg B.M. and Zhang J.W., 2001. Physiology and morphology of Pinus sylvestris seedlings from diverse sources under cyclic drought stress. Forest. Ecol. Manage 154: 131-139.

Danjon F., 1994. Stand features and height growth in a 36-year-old maritime pine (Pinus pinaster Ait.) provenance test. Silvae Genet. 43: $52-62$.

Fernández M., Gil L., and Pardos J.A., 1999. Response of Pinus pinaster Ait. provenances at early age to water supply. I. Water relation parameters. Ann. For. Sci. 56: 179-187.

Fernández M., Gil L., and Pardos J.A., 2000. Effects of water supply on gas exchange in Pinus pinaster Ait. provenances during their first growing season. Ann. For. Sci. 57: 9-16.

González-Martínez S.C., Alía R., et al., 2002. Population genetic structure in a Mediterranean pine (Pinus pinaster Ait.): a comparison of allozyme markers and quantitative traits. Heredity 89: 199-206.

Gonzalo J., 2008. Diagnosis fitoclimática de la España peninsular actualización y análisis geoestadístico aplicadoDepartamento de Silvopascicultura, ETSI Montes, Universidad Politécnia de Madrid (UPM), Madrid, p. 521.

Guyon J.P. and Kremer A., 1982. Stabilité phénotypique de la croissance en hauteur et cinétique journalièr de presión de sève et de la transpiration chez le pin maritime (Pinus pinaster Ait.). Can. J. For. Res. 12: 936-946.

IPCC, 2007. Climate change 2007. The physical science basis: working group I contribution to the fourth assessment report of the IPCC, Cambridge University Press, Cambridge, UK.

Jones H.G., 1993. Drought tolerance and water-use efficiency. In: Smith J.A.C. and Griffiths H. (Eds.), Water Deficits: Plant Responses from Cell to Community, BIOS Scientific Publishers, Oxford, UK, pp. 193-203.
Körner C., 2003. Alpine Plant Life - Functional plant ecology of high mountain ecosystems, Springer-Verlag, Berlin, 344 p.

Leck M.A., Parker V.T., and Simpson R.L., 2008. Seedling ecology and evolution, Cambridge University Press, Cambridge, UK.

Ludlow M.M., 1989. Strategies of response to water stress. In: Kreeb K.H., Richter H., and Hinckley T.M. (Eds.), Structural and functional responses to environmental stresses, SPB Academic Publishing, The Hague, pp. 269-281.

Müller I., Schmid B., and Weiner J., 2000. The effect of nutrient availability on biomass allocation patterns in 27 species of herbaceous plants. Perspect. Plant Ecol. Evol. Syst. 3: 115-127.

Nguyen-Queyrens A. and Bouchet-Lannat F., 2003. Osmotic adjustment in three-year-old seedlings of five provenances of maritime pine (Pinus pinaster) in response to drought. Tree Physiol. 23: 397-404.

Nguyen-Queyrens A., Ferhi A., Lousteau D., and Guehl J.M., 1998. Within-ring delta $\mathrm{C}-13$ spatial variability and interannual variations in wood cellulose of two contrasting provenances of Pinus pinaster. Can. J. For. Res. 28: 766-773.

Nguyen A. and Lamant A., 1989. Variation in growth and osmotic regulation of roots of water-stressed maritime pine (Pinus pinaster Ait.) provenances. Tree Physiol. 5: 123-133.

Pigott C.D. and Pigott S., 1993. Water as a determinant of the distribution of trees at the boundary of the Mediterranean zone. J. Ecol. 81: 557566.

Poorter H. and Nagel O., 2000. The role of biomass allocation in the growth response of plants to different levels of light, $\mathrm{CO}_{2}$, nutrients and water: a quantitative review. Aus. J. Plant Physiol. 27: 595-607.

Poorter L., 2001. Light-dependent changes in biomass allocation and their importance for growth of rain forest tree species. Funt. Ecol. 15: 113-123.

Popma J. and Bongers F., 1988. The effect of canopy gaps on growth and morphology of seedlings of rain forest species. Oecologia 5: 625632.

Richards R.A. and Townley-Smith T.F., 1987. Variation in leaf area development and its effect on water use, yield and harvest index of droughted wheat. Aust. J. Agric. Res. 38: 983-992.

Sáenz-Romero C., Guzmán-Reyna R.R., and Rehfeldt G.E., 2006. Altitudinal genetic variation among Pinus oocarpa populations in Michoacán, Mexico. Implications for seed zoning, conservation, tree breeding and global warming. For. Ecol. Manage. 229: 340-350.

Sánchez-Gómez D., Zavala M.A., and Valladares F., 2008. Functional traits and plasticity linked to seedlings' performance under shade and drought in Mediterranean woody species. Ann. For. Sci. 65: 311.

Schlichting C.D., 1986. The evolution of phenotypic plasticity in plants. Ann. Rev. Ecol. Syst. 17: 667-693.

Shugart H.H., 1984. A theory of forest dynamics: the ecological implications of forest succession models, Springer-Verlarg, New York, $278 \mathrm{p}$.

Tilman D., 1988. Plant strategies and the dynamics and structure of plant communities, Princeton University Press, Princeton, New Jersey, USA.

Visscher P.M., 1998. On the sampling variance of intraclass correlations and genetic correlations. Genetics 149(1605-1614).

Wahid N., González-Martínez S.C., El Hadrami I., and Boulli A., 2006. Variation of morphological traits in natural populations of maritime pine (Pinus pinaster Ait.) in Morroco. Ann. For. Sci. 63: 83-92.

White T.L., Adams W.T., and Neale D.B., 2007. Forest Genetics, CAB International, Trownbridge, UK, $682 \mathrm{p}$.

Wilson J.B., 1988. A review of evidence on the control of shoot:root ratio, in relation to models. Ann. Bot. 61: 433-449.

Zhang J.W., Feng Z., Gregg B.M., and Schuman C.M., 1997. Carbon isotopic composition, gas exchange, and growth of three populations of ponderosa pine differing in drought tolerance. Tree Physiol. 17: 461-466.

Zhang J.W., Marshall J.D., and Fins L., 1996. Correlated population differences in dry matter accumulation, allocation, and water-use efficiency in three sympatric conifer species. For. Sci. 42: 242-249. 